\title{
Challenges in quantifying long-term air- water carbon dioxide flux using estuarine water quality data: Case study for Chesapeake Bay
}

Maria Herrmann ${ }^{1}$, Raymond G. Najjar ${ }^{1}$, Fei Da ${ }^{2}$, Jacyln Friedman $^{2}$, Marjorie A. M. Friedrichs ${ }^{2}$, Sreece Goldberger ${ }^{1}$, Alana Menendez ${ }^{3}$, Elizabeth $\mathrm{H}$. Shadwick $^{4}$, Edward G. Stets ${ }^{5}$, and Pierre St-Laurent ${ }^{2}$

${ }^{1}$ Department of Meteorology and Atmospheric Science, The Pennsylvania State University, University Park, PA, USA; mxh367@psu.edu; rgn1@psu.edu;

${ }^{2}$ Virginia Institute of Marine Science, William \& Mary, Gloucester Point, VA, USA

${ }^{3}$ Department of Earth and Atmospheric Sciences, The City College of New York, City University of New York, New York, NY, USA

${ }^{4}$ CSIRO, Oceans \& Atmosphere, Hobart, TAS, Australia

${ }^{5}$ United States Geological Survey, Mounds View, MN, USA

Estuaries play an uncertain but potentially important role in the global carbon cycle via $\mathrm{CO}_{2}$ outgassing. The uncertainty mainly stems from the paucity of studies that document the full spatial and temporal variability of estuarine surface-water partial pressure of carbon dioxide $\left(\mathrm{pCO}_{2}\right)$. Here, we explore the potential of utilizing the abundance of $\mathrm{pH}$ data from historical water quality monitoring programs to fill the data void via a case study of the mainstem Chesapeake Bay (eastern United States). We calculate $p \mathrm{CO}_{2}$ and the air-water $\mathrm{CO}_{2}$ flux at monthly resolution from 1998 to 2018 from tidal fresh to polyhaline waters, paying special attention to the error estimation. The biggest error is due to the $\mathrm{pH}$ measurement error, and errors due to the gas transfer velocity, temporal sampling, the alkalinity mixing model, and the organic alkalinity estimation are $72,27,15$, and $5 \%$, respectively, of the error due to $\mathrm{pH}$. Seasonal, interannual, and spatial variability in the air-water flux and surface $p \mathrm{CO}_{2}$ is high, and a correlation analysis with oxygen reveals that this variability is driven largely by biological processes. Averaged over 1998-2018, the mainstem bay is a weak net source of $\mathrm{CO}_{2}$ to the atmosphere of $1.2(1.1,1.3) \mathrm{mol} \mathrm{m}^{-2} \mathrm{yr}^{-1}$ (best estimate and $95 \%$ confidence interval). 